https://helda.helsinki.fi

Peircean abduction : instinct or inference?

Paavola, Sami

2005

Paavola, S 2005 , ' Peircean abduction : instinct or inference? ' , Semiotica, vol. 153 , no.

1-4, pp. [131]-154.

http://hdl.handle.net/10138/225800

publishedVersion

Downloaded from Helda, University of Helsinki institutional repository.

This is an electronic reprint of the original article.

This reprint may differ from the original in pagination and typographic detail.

Please cite the original version. 


\title{
Peircean abduction: Instinct or inference?
}

\author{
SAMI PAAVOLA
}

Peirce's conception of abduction has many puzzling features. Some of these puzzles follow from the fact that Peirce developed his theory of abduction throughout his long career, and changed his views in some important respects. This development should then be taken into account when his multi-faceted conception of abduction is interpreted. One important change was that, in his later writings, a guessing instinct, or an instinct for finding good hypotheses, was an important aspect of abduction, indeed, a central element that made the originary character of abduction understandable. Earlier, he had rejected this role explicitly.

The strong appeal to instinct raises, however, a fundamental problem for his later view. It leads to a seemingly paradoxical view that new ideas and hypotheses are products of an instinct (or an insight), and products of an inference at the same time (Frankfurt 1958: 594; see also Fann 1970: 35; Anderson 1987: 32, 35; Roth 1988; Brogaard 1999; Burton 2000). Can abduction be, at the same time, a form of reasoning and have its basis so clearly in instinct? Usually it is thought that new ideas are products of an imaginative faculty of human beings, which is a matter of psychology (or maybe sociology), or contrary-wise, of a rational or rule-following procedure, which would mean that one could develop some sort of a logic of discovery; but not these two at the same time or with the same model. If abduction relies on instinct, it is not a form of reasoning, and if it is a form of reasoning, it does not rely on instinct.

In this article, I examine how it is interpreted that Peirce succeeded in combining instinct and inference; and, more generally, how to see the relationship between these two. I first present, briefly, some basic phases of Peirce's conception of abduction, and differing characterizations that may be found for instinct in Peirce's writings. Then I will discuss other interpeters' accounts of how Peirce combines instinct and inference. Finally I present my own interpretation of this relationship and give my own assessment. To foreshadow, I maintain that it is beneficial to make a clear distinction between abductive inference and abductive instinct, and 
to develop these both further. I argue that although this interpretation differs from Peirce's own conception, especially according to his later view, it can be supported by Peirce's own writings.

\title{
1. The evolution of Peirce's conception of abduction
}

Peirce's writings concerning abduction range over almost 50 years time, so it is no wonder that they contain elements for various interpretations. ${ }^{1}$ It is customary to separate two periods in Peirce's conceptions of abduction, although there was no abrupt change in his views (Burks 1946: 301; Fann 1970: 9-10; Thagard 1981; Anderson 1986, 1987: 19-23; Flach and Kakas 2000: 5-8; Paavola 2004b). In the early period (from the 1860s to about the 1890s) abduction was seen by Peirce as an evidencing process, i.e., as a weak kind of a syllogistic inference, differing from deduction and induction. A basic formulation of abduction is an inversion of deductive, Barbara syllogism so that the minor premise is abduced from the conclusion and the major premise. Abduction is, then, a weak form of inference:

\author{
HYPOTHESIS [ABDUCTION] \\ Rule - All the beans from this bag are white. \\ Result - These beans are white. \\ $\therefore$ Case - These beans are from this bag. \\ (CP 2.623, 1878)
}

In the later period (about 1890s onwards) abduction was seen by Peirce from a methodological viewpoint rather than as a relationship between premises and a conclusion. Abduction is a first phase of inquiry with which ideas are generated. A basic formula of abduction is quite similar to the earlier formula:

The surprising fact, $\mathrm{C}$, is observed; [cf. Result]

But if $\mathrm{A}$ were true, $\mathrm{C}$ would be a matter of course, [cf. Rule]

Hence, there is reason to suspect that $\mathrm{A}$ is true. [cf. Case]

(CP 5.189, 1903)

But, differing from the evidential viewpoint, the methodological viewpoint emphasizes that abduction is one phase in the process of inquiry; hypotheses and ideas are generated with abduction and should then be tested with deduction and induction (CP 6.469-6.473, 1908; CP 7.202219, 1901). 
Actually, a clearer change in Peirce's views than from evidential to methodological perspective concerned the role of instinct in abduction. In his earlier view, he saw no need for, or indeed rejected a connection between instinct and abductive inference, whereas, according to his later view, the guessing instinct is a central element within abduction.

The early view is manifest at the end of his paper 'A Theory of Probable Inference,' from 1883. There, Peirce maintained that 'all human knowledge, up to the highest flights of science, is but the development of our inborn animal instincts' ( $C P$ 2.754, 1883; see also CP 6.416-6.417, 1878) but he argued that this fact does not affect the validity of abductive inference:

Others have supposed that there is a special adaptation of the mind to the universe, so that we are more apt to make true theories than we otherwise should be. Now, to say that a theory such as these is necessary to explaining the validity of induction and hypothesis [i.e. abduction] is to say that these modes of inference are not in themselves valid, but that their conclusions are rendered probable by being probable deductive inferences from a suppressed (and originally unknown) premiss. (CP 2.749, 1883; see also NEM 3: 227-228, 1866; CP 5.345, 1869)

According to his later view, abduction is supposed to be the way to generate new ideas and suggestions for further inquiry and testing. Peirce emphasized that abduction is a weak mode of inference coming close to, or even being the same as guessing (HP 2: 878-879, 1900; CP 7.219, 1901; NEM 4: 319-320, c. 1906). But, despite its weakness, it is of utmost importance because it is the only mode of inference that introduces new ideas (CP 5.171, 1903; $C P$ 5.590, 1903; CP 6.475, 1908). Yet abduction is not supposed to be pure guessing, or a procedure based on pure chance operations (Brogaard 1999: 130-131). This is where Peirce introduces the need for instinct.

... [I]t is a primary hypothesis underlying all abduction that the human mind is akin to the truth in the sense that in a finite number of guesses it will light upon the correct hypothesis. Now inductive experience supports that hypothesis in a remarkable measure. For if there were no tendency of that kind, if when a surprising phenomenon presented itself in our laboratory, we had to make random shots at the determining conditions, trying such hypotheses as that the aspect of the planets had something to do with it, or what the dowager empress had been doing just five hours previously, if such hypotheses had as good a chance of being true as those which seem marked by good sense, then we never could have made any progress in science at all. (CP 7.220, 1901; also CP 1.80-1.81, c. 1896; HP 2: 900901, 1901; CP 5.591, 1903) 
New ideas could not have been produced by chance operations; there simply has not been enough time for that in human history. So, according to this, one must suppose some sort of an instinct that helps human beings to find true hypotheses, otherwise the progress of science would be inexplicable. Peirce also maintains that it actually seems to be the case that we humans have this kind of an instinct. This guessing instinct is not claimed to be infallible, but still good enough to help find right hypotheses much more effectively than pure chance operations would allow (CP 6.476, $1908 ; C P 7.220,1901)$. So there is a need for an 'abductive instinct' and also reasons for thinking that we actually have this kind of an instinct.

Peirce's later view of abduction can be interpreted so that it means either the way new hypotheses are generated or formed in the first place (the 'generative' sense), or, in addition to this generative sense, the way these hypotheses are evaluated in a preliminary way (the 'evaluative' sense) (see Nickles 1980: 18-23; Kapitan 1992; Paavola 2004b). In both of these versions, abductive instinct is especially important in the generative phase of discovery (cf. Shanahan 1986). Instinct helps researchers to find good hypotheses although there then can be 'reasoned' considerations (like questions concerning the economy of research) besides these instinctive ones (CP 7.220, 1901).

\section{Forms of abductive instinct}

It is not clear what Peirce means by abductive, guessing instinct. In various writings, Peirce gives somewhat different bases and characterizations for it. According to Shanahan (1986), Peirce offers three distinct but interwoven grounds for justifying abductive instinct: (1) naturalistic, (2) idealistic (or metaphysical), and (3) theistic justification, which give three basic ways for understanding the nature of abductive instinct. I first present all these briefly, and then analyze various accounts of the 'naturalistic' basis.

1. A naturalistic basis means that Peirce likens abductive instinct to those instincts that animals possess for getting food and reproducing (HP 2: 900-901, 1901). If animals have innate tendencies that help them to survive in their environments, why not to assume that we as human beings have analogously innate tendencies for finding correct theories? This kind of an instinct would obviously have strong adaptive value for us.

2. For Peirce, the naturalistic arguments were closely linked to idealistic grounds for abductive instinct; 'It is somehow more than a mere figure of speech to say that nature fecundates the mind of man with 
ideas which, when those ideas grow up, will resemble their father, Nature' (CP 5.591, 1903). This is in line with Peirce's synechism (which he developed especially after 1890s), according to which everything is continuous (Shanahan 1986: 459-462): Mind and matter are not entirely distinct elements but 'all phenomena are of one character, though some are more mental and spontaneous, others more material and regular' (EP 2: 2, 1893; see also Bergman and Paavola 2003, entry: 'Synechism'). Similarly, it can be argued that there is no sharp line between instinct and inference; 'instinct and reason shade into one another by imperceptible gradations' (NEM 3: 1114). The metaphysical ground is a rather vague argument for the idea that if the human mind is developed under those laws that govern the universe, it is reasonable to suppose that the mind has a tendency to find true hypotheses concerning this universe. In this way, general considerations concerning the universe, strictly philosophical considerations, all but demonstrate that if the universe conforms, with any approach to accuracy, to certain highly pervasive laws, and if man's mind has been developed under the influence of those laws, it is to be expected that he should have a natural light, or light of nature, or instinctive insight, or genius, tending to make him guess those laws aright, or nearly aright. (CP 5.604, 1903; cf. CP 6.10, 1891). This natural light, or il lume naturale, is no guarantee of the truth by itself, but it is supposed to be an essential factor that helps us to find true theories (CP 1.80, c. 1896; CP 1.630, 1898).

3. In some of his writings, these metaphysical grounds for abduction were also interwoven with what can be called theistic arguments. Retroduction [i.e. abduction] gives hints that come straight from our dear and adorable Creator. We ought to labour to cultivate this Divine privilege. It is the side of human intellect that is exposed to influence from on high. (NEM 3: 206, 1911; see also CP 8.212, c. 1905; $C P$ 6.476-6.477, 1908; MS 843 [variant]: 7)

These theistic arguments are rather indefinite. Shanahan concludes that, according to Peirce,

[p]resumably God is a rational creator; man is made to God's image; therefore man has within him the ability to contemplate and intellectually penetrate to some degree the rational plan at work in nature, i.e., God's thoughts expressed in laws of nature. (Shanahan 1986: 464)

This account is intervowen with the Kantian idea that processes of nature and processes of thought are alike ( $C P 3.422,1892)$. These theistic 
arguments also have affinities to Peirce's idea of agapastic evolution, i.e., to an idea that the 'law of love' is operative in cosmos (EP 1: 352-371, 1893; Kim and Cunningham 2003: 310). According to Peirce, evolution by fortuitous variation ('tychastic evolution'), or evolution by mechanical necessity ('anancastic evolution') is not enough; we need agapistic evolution (EP 1: 362, 1893). These three variations of evolution also concern the development of thought.

The agapastic development of thought is the adoption of certain mental tendencies, not altogether heedlessly, as in tychasm, nor quite blindly by the mere force of circumstances or of logic, as in anancasm, but by an immediate attraction for the idea itself, whose nature is divined before the mind possesses it, by the power of sympathy, that is, by virtue of the continuity of mind. (EP 1: 364, 1893)

One aspect of agapastic evolution, then, is that there is alleged to be some sort of a 'continuity between man's mind and the Most High' (ibid.).

\section{Varieties of naturalistic grounds}

Peirce's naturalistic grounds for abductive instinct can also be seen to contain various ingredients. Or, various writings of Peirce concerning abductive instinct can be seen to have differing emphases, especially when interpreted through the eyes of a modern reader. For Peirce himself, these various aspects of abductive instinct are more or less meant as alternative ways for describing the same phenomenon, but it is useful to distinguish these characterizations. I want to discern three main varieties of naturalistic abductive instinct: a) 'adaptive instinct,' b) 'perceptual insight,' and c) 'guessing with non-conscious clues.' These varieties overlap each other, but if differently emphasized, they lead to quite different interpretations of the proposed abductive instinct.

a) Peirce offers various evolutionary or adaptive arguments for the guessing instinct. Peirce likens this 'adaptive instinct' to those basic instincts that animals have for survival:

Besides, you cannot seriously think that every little chicken, that is hatched, has to rummage through all possible theories until it lights upon the good idea of picking up something and eating it. On the contrary, you think the chicken has an innate idea of doing this; that is to say, that it can think of this, but has no faculty of thinking anything else. The chicken you say pecks by instinct. But if you are going to think every poor chicken endowed with an innate tendency toward a positive truth, why should you think that to man alone this gift is denied?... In short, the 
instincts conducive to assimilation of food, and the instincts conducive to reproduction, must have involved from the beginning certain tendencies to think truly about physics, on the one hand, and about psychics, on the other. (CP 5.591, 1903; also CP 6.531, 1901; CP 7.39-7.40, c. 1907)

According to this argument, the human being should have some innate tendencies for finding true theories, especially concerning physics and 'psychics' otherwise he or she would not have succeeded in the environment. These biological arguments were closely connected to metaphysical arguments for the abductive instinct, as already given: Nature is alleged to 'fecundate' the mind of the man with the true theories (ibid.).

The arguments for innate tendencies were intertwined with the idea of habit change through experience. I will not analyze, in detail, Peirce's conception of evolution or the evolutionary theory which has both Darwinian and Lamarckian elements in it, and which is closely linked to his evolutionary metaphysics (see e.g., CP 6.287-6.317, 1893; Roth 1988). At any rate, Peirce's conception of instinct was quite broad. Instincts can, according to Peirce, undergo modification and change by new experience (CP 1.648, 1898; EP 2: 467, 1913). So, besides innate tendencies, instincts also cover learned habits.

If I may be allowed to use the word "habit," without any implication as to the time or manner in which it took birth, so as to be equivalent to the corrected phrase "habit or disposition," that is, as some general principle working in a man's nature to determine how he will act, then an instinct, in the proper sense of the word, is an inherited habit, or in more accurate language, an inherited disposition. But since it is difficult to make sure whether a habit is inherited or is due to infantile training and tradition, I shall ask leave to employ the word "instinct" to cover both cases. (CP 2.170, c. 1902)

b) In his famous, 1903 Pragmatism lectures Peirce likens the guessing instinct to insight and perception. So on this approach, the guessing instinct is a form of a 'perceptual insight' rather than instinct as such. Peirce himself describes the relationship between insight and instinct:

It appears to me that the clearest statement we can make of the logical situation - the freest from all questionable admixture - is to say that man has a certain Insight, not strong enough to be oftener right than wrong, but strong enough not to be overwhelmingly more often wrong than right, into the Thirdnesses, the general elements, of Nature. An Insight, I call it, because it is to be referred to the same general class of operations to which Perceptive Judgments belong. This Faculty is at the same time of the general nature of Instinct, resembling the instincts of the animals in its so far surpassing the general powers of our reason and for its 
directing us as if we were in possession of facts that are entirely beyond the reach of our senses. It resembles instinct too in its small liability to error; for though it goes wrong oftener than right, yet the relative frequency with which it is right is on the whole the most wonderful thing in our constitution. $(C P$ 5.173, 1903)

According to these lectures, abduction has close affinities to perception and perceptual judgments. In a famous passage, Peirce wrote that abduction

... shades into perceptual judgment without any sharp line of demarcation between them; or, in other words, our first premisses, the perceptual judgments, are to be regarded as an extreme case of abductive inferences, from which they differ in being absolutely beyond criticism. (CP 5.181, 1903)

Perceptual judgments are supposed to be similar processes to abductive inference, except that processes of forming perceptual judgments are subconscious, and not amenable to logical criticism (ibid.). Reversible figures, i.e. visual data that can be interpreted in several ways, are borderline cases between perceptual judgments and abductive inferences because they show that percepts contain inferential or interpretative elements (see CP 5.183-5.184, 1903; also Hanson 1958; Burton 2000: 151).

If perception, then, is dependent on abductive inference, abduction, on the other hand, is dependent on perception. After presenting the formula for abduction (CP 5.189, 1903; or see above), Peirce continues:

Thus, A cannot be abductively inferred, or if you prefer the expression, cannot be abductively conjectured until its entire content is already present in the premiss, "If A were true, $\mathrm{C}$ would be a matter of course." (ibid.)

And this means that 'all conceptions must be given substantially in perception' (CP 5.191, 1903). So accordingly, perception is a precondition for abductive inference.

c) In the paper, 'Guessing,' Peirce describes in a lively way how the 'guessing instinct' of humans can operate (Peirce 1929 [or MS 687]2). Peirce admits: 'There are, indeed, puzzles, and one might well say mysteries, connected with the mental operation of guessing - yes more than one' (Peirce 1929: 269 [CP 7.39, c. 1907]).

In this paper Peirce proceeds to offer, explicitly, 'two principles which I have been led to conjecture furnish at least a partial explanation of the mystery that overhangs this singular guessing instinct.' (ibid.: 281 [CP 7.46 , c. 1907]). One of these is the idealistic (or metaphysical) argument, 
already discussed above, that 'man's mind, having been developed under the influence of the laws of nature, for that reason naturally thinks somewhat after nature's pattern.' (ibid.: 269 [CP 7.39, c. 1907]) The other one is

that we often derive from observation strong intimations of truth, without being able to specify what were the circumstances we had observed which conveyed those intimations. (ibid.: 282 [CP 7.46, c. 1907])

This is a third variety of the naturalistic abductive instinct that I call 'guessing with non-conscious clues.'

Peirce delineates this form of the guessing instinct by telling a story how he himself operated as a detective by catching a crook who had stolen his valuable watch and an overcoat on a boat trip (Peirce 1929; see Eco and Sebeok 1983). As Peirce says, this story is anecdotal, but he maintains that it is a true story. In any case, it provides one form of Peirce's guessing instinct. I am not going to describe all the incidents involved in this story. One key event, however, was that Peirce asked all waiters who were suspects, for the theft, to the deck to stand in a row. He was hoping to gain some clues about the culprit.

I went from one end of the row to the other, and talked a little to each one, in as dégagé a manner as I could, about whatever he could talk about with interest, but would least expect me to bring forward, hoping that I might seem such a fool that I should be able to detect some symptom of his being the thief. (Peirce 1929: 271)

This procedure was not successful, but he felt he had to get his belongings back, especially the watch he had gotten from his workplace for the U.S. Coast Survey. So he had to use his instinct for guessing:

When I had gone through the row I turned and walked from them, though not away, and said to myself, "Not the least scintilla of light have I got to go upon." But thereupon my other self (for our own communings are always dialogues), said to me, "But you simply must put your finger on the man. No matter if you have no reason, you must say whom you will think to be the thief." I made a little loop in my walk, which had not taken a minute, and as I turned toward them, all shadow of doubt had vanished. (ibid.)

Later, it turned out that he had chosen the right person. The point is that he recognized no clues or signs of the culprit, but still guessed right; and was even certain that he got it right. Peirce was not able to persuade the culprit to return his things, so he had to go to a detective's office with his suspicions, and ask them to shadow this suspect. After he had told his suspicions, Mr. Bangs [a detective in the office] said: 
"What makes you think he [this particular waiter] has stolen your watch?" "Why," said I [Peirce], "I have no reason whatever for thinking so; but I am entirely confident that it is so." (ibid.: 273)

But, on the other hand, when trying to give an explanation for these phenomena, Peirce refers to psychological experiments that he had carried out with Joseph Jastrow in the 1880s, which showed that people are able to perceive changes of stimulus (pressure in their fingertips) even when they are not conscious of these changes, i.e. to notice (or 'guess') changes of stimulus, by using subconscious clues, more often than would be expected by pure chance. Peirce maintains that selfconsciousness can even weaken this kind of a performance, and instinct works better spontaneously.

While I was going through the row, chatting a little with each, I held myself in as passive and receptive a state as I could. When I had gone through the row I made a great effort to detect in my consciousness some symptoms of the thief, and this effort, I suppose, prevented my success. But then finding I could detect nothing I said to myself, "Well, anyway, I must fasten on someone, though it be but a random choice," and instantly I knew which of the men it was. (ibid.: 281)

This third form of the guessing instinct has close affinities to 'perceptual insight' (item 2 above). But, whereas in Pragmatism lectures from 1903 Peirce likens the guessing instinct to perception and perceptual judgments as such, in this third form, small observational symptoms and clues which are not even consciously recognized, are emphasized.

\section{The relationship between instinct (or insight) and inference}

How then, did Peirce manage to combine abduction as a mode of inference with the idea that it is at the same time crucially dependent on instinct, or insight. One answer is to say that Peirce did not succeed in this. Braithwaite has maintained that actually Peirce differs from the 'orthodox' account only verbally, i.e. by calling an act of insight, reasoning (Braithwaite 1934: 509-510; see also Frankfurt 1958). So according to this view, the process of discovery is not amenable to logic, but is a matter of psychology (or sociology, history, and so on). There are some passages of Peirce which may be interpreted to support this view:

Any novice in logic may well be surprised at my calling a guess an inference. It is equally easy to define inference so as to exclude or include abduction. But all the objects of logical study have to be classified; and it is found that there is 
no other good class in which to put abduction but that of inferences. (HP 2: 899, 1901)

This argument is fortified when it is noticed that, in the formulations of abduction, the hypothesis or the idea is already in the premises. Abduction (as a guessing instinct) is supposed to be a way of generating novel ideas and hypotheses, whereas in the inferential formulas of abduction the idea or the hypothesis in question is already supposed to be known (e.g. Frankfurt 1958: 594; Kapitan 1990: 499; Hoffmann 1999: 278-9). So it seems that abduction as an instinct and abduction as an inference are meant for different purposes. At most, abduction as an inference is a way of evaluating, in a preliminary way, those ideas that abduction as an instinct has produced for the inquirer (see also Nickles 1980: 23-25). And, according to this argument, this is not much different from the orthodox view (e.g., from the traditional hypothetico-deductive model of inquiry) where the invention of hypotheses is the area of instinct and psychology, and logic and reasoning deal only with the subsequent evaluation of these hypotheses (Kapitan 1992).

Many Peirce scholars have, however, rejected the interpretation that Peirce only called creative insight or guessing instinct an inference. At least Peirce himself was aiming at something else (Fann 1970: 36). This position can be backed up by various quotations. When talking about Speculative Rhetoric or Methodeutic, he wrote:

... after the main conceptions of logic have been well settled, there can be no serious objection to relaxing the severity of our rule of excluding psychological matter, observations of how we think, and the like. The regulation has served its end; why should it be allowed now to hamper our endeavors to make methodeutic practically useful? But while the justice of this must be admitted, it is also to be borne in mind that there is a purely logical doctrine of how discovery must take place ... (CP 2.107, c. 1902, emphasis added; Fann 1970: 36)

Or:

It must be remembered that abduction, although it is very little hampered by logical rules, nevertheless is logical inference, asserting its conclusion only problematically or conjecturally, it is true, but nevertheless having a perfectly definite logical form. (CP 5.188, 1903, emphasis added; Anderson 1987: 33)

There are several interpretations of how Peirce himself managed, or thought he managed, to combine instinct and inference together. According to Fann, Peirce discussed both psychological aspects and logical aspects of discovery, but the intent was to keep them separate. So when 
Peirce wrote about 'insight' or 'the affinity of mind with nature,' he was talking about psychological matters, not logical (Fann 1970: 35-38). Similarly, Burks has suggested that when Peirce used words, such as 'insight', and 'instinct,' he was talking about human's logica utens, that is, an undeveloped theory of logic, or practical ways of making inferences. This logica utens can then be developed with logica docens, that is, with a critical and scientific theory of logic (Burks 1946: 302-303). Burks admits that Peirce himself did not use this distinction between logica utens and logica docens in relationship to abduction but, according to Burks, it makes Peirce's ideas more tenable.

It seems, however, that Peirce himself, in his later writings, did not keep instinct so separate from logic, at least from that part of logic that he called "Methodeutic" (see MS 633: 3, 1909; cf. Paavola 2004b). Instinct was rather supposed to play an essential role in abduction, also in the sense of logica docens:

The reason for accepting the Retroductive [i.e., Abductive] conclusion, is that man must trust to his power of getting at the truth simply because it is all he has to guide him; and moreover when we look at the instincts of various animals, we are struck with wonder at how they lead those creatures toward rational behaviour. (NEM 3: 203-204, 1911)

So abduction is sometimes characterized by Peirce as the same as the process of instinctive reason: '.. by Retroduction ... that is to say, by the spontaneous conjectures of instinctive reason ...' $(C P 6.475,1908)$

There are more recent interpreters of abduction who maintain that instinct (or insight) is an important aspect of abduction, but in the sense that it is one element within abduction. Accordingly, novel ideas and hypotheses are suggested by instinctual (or perceptual) process, but not everything suggested is inferred abductively, so there is a need for close interaction with inferential and instinctual elements in abduction (e.g., Kapitan 1990: 503-507; 1992: 7-11; 1997: 481-484). This interpretation has its basis especially in Peirce's 1903 lectures on pragmatism, where Peirce emphasizes a close affinity of abduction to perception and perceptual judgments. Hoffmann has supported this interpretation by separating inferential and perceptive elements in abduction (Hoffmann 1999). Perceptive elements are the creative side of abduction. 'The explaining idea emerges in perceiving facts and experiences, and not in the conclusion of an inference' (Hoffmann 1999: 279). The form of inference is abductive, but the creative part is how to get the hypothesis to the second premise, and this is not the question of the inferential side but of the perceptive side. It might then be proposed that the perceptive aspect is responsible 
for the discovery in the generative sense, and the inferential aspect in evaluative sense (in a preliminary way, i.e., if the hypothesis is worth further inquiry and testing).

According to Douglas R. Anderson, insight and inference cannot, however, be separated in abduction. He clearly defends the view that, for Peirce, abduction is '.. both an insight and an inference. This is a fact to be explained, not to be explained away ... Peirce quite intentionally conjoined insight and inference in his description of abduction' (Anderson 1987: 33).

I agree with Anderson that this seems, at least, to be Peirce's own overall intention in his later writings. Usually Peirce himself did not want to make any sharp distinction between the elements within abduction, and instinct and inference 'shade into' each other, without any clear separating line (cf. CP 5.181, 1903). But it is not easy to see how Peirce thinks that this can be done. Anderson gives various arguments for this interpretation (ibid.: 32-50). He maintains that the logical form of abduction (that the hypothesis searched for is already in the premises) does not preclude abduction as a logic of discovery. Anderson also argues that, if instinct is not deterministic (i.e., that it would determine our guesses), it leaves room for logical form. Instinct is supposed to be an ability that is a necessary, but not a sufficient condition for abduction (ibid.: 36-37). But these arguments are problematic. Even though instinct is not supposed to be deterministic, still, if this instinct is a central factor for helping us humans to find good hypotheses, it seems that, in this sense, abduction is not just a matter of logic any more, but rather a matter of psychology.

From Peirce's point of view, it is important that insight or instinct does not mean an unmediated intuition (Anderson 1987: 37-39). In contrast to intuition, abduction is fallible, it requires work by the investigator, and it needs contextual knowledge and experience to begin with (ibid.). Abduction combines compulsion, control and free play: 'Abduction is inference because the agent is free to control his reasoning and it is insight because it allows ideas to suggest other ideas' (ibid.: 44; cf. also Peirce's ideas of 'Play of Musement,' CP 6.452-6.465, 1908). A central element of reasoning is that it is deliberate and self-controlled (I will come back to this in the next section), and this creates a tension between instinct and inference; it is typically thought that inference is something that is under conscious control of the inquirer whereas instincts force us without conscious control (see Kapitan 1992: 8). But Peirce's idea seems to be that, on one hand, to us humans instinct can be under some control, and on the other hand, with abductive inference the element of control is not so strong as with other forms of reasoning (see Burton 2000). So abduction can 
be seen as a borderline case, which is 'the closest reasoning gets to nonreasoning' (Anderson 1987: 42; see MS 831: 13-14). The guessing instinct combines elements that are at the same time compelled and under our control:

The first answer we naturally give to this question is that we cannot help accepting the conjecture at such a valuation as that at which we do accept it; whether as a simple interrogation, or as more or less Plausible, or, occasionally, as an irresistible belief. But far from constituting, by itself, a logical justification such as it becomes a rational being to put forth, this pleading, that we cannot help yielding to the suggestion, amounts to nothing more than a confession of having failed to train ourselves to control our thoughts. It is more to the purpose, however, to urge that the strength of the impulse is a symptom of its being instinctive. (CP 6.476, 1908)

For man, instinct is partly conscious; it is 'always partially controlled by the deliberate exercise of imagination and reflexion' (CP $7.381 \mathrm{n}$. 19, c. 1902). According to Peirce, there is some sort of a continuum from animal instinct that is determinate and well adapted for certain purposes, to human instinct that is more flexible but at the same time more fallible (EP 2: 467-468, 1913), and finally to reasoning that is fallible but more amenable to novel situations (see $C P$ 6.497, c. 1906). So it seems that, according to Peirce, instinct and abductive inference can more or less merge if the special characteristics of both of them are taken into account; 'Reason is a sort of instinct' (EP 2: 472, 1913; see also EP 2: 464).

I maintain that there is still at least one possible way of seeing the connection between instinct and inference through Peirce's writings; this interpretation develops abduction as a form of inference that is essential in discovery. On the other hand, it is advantageous to analyze those processes that are similar to inference but not inference in the proper sense; and these processes are closely related to instinct. According to this interpretation, abductive inference and the guessing instinct (or different forms of the guessing instinct) can be seen as separate but closely analogous processes. Although Peirce himself did not keep this distinction in his later writings, it is reasonable to do so, and there are also good arguments, from Peirce himself, for doing so. For this reason, I will next analyze abductive inference, as distinct from abductive instinct.

\section{The nature of abductive inference}

I maintain that Peirce need not have merged inference and instinct in his later writings. This view of inference is in line with Peirce's early view ( $C P$ 
$2.749,1883)$, but there are also many passages around the turn of the century that support this perspective. According to these, reasoning is deliberate and controlled (see also Brogaard 1999), for example:

Reasoning, properly speaking, cannot be unconsciously performed. A mental operation may be precisely like reasoning in every other respect except that it is performed unconsciously. But that one circumstance will deprive it of the title of reasoning. For reasoning is deliberate, voluntary, critical, controlled, all of which it can only be if it is done consciously. (CP 2.182, c. 1902 ; see also HP 2: 891, 1901)

Peirce continues,

[t]his does not imply that we must be aware of the whole process of the mind in reasoning or, indeed, of any portion of it [-] all that is necessary is that we should, in each case, compare premisses and conclusion, and observe that the relation between the facts expressed in the premisses involves the relation between facts implied in our confidence in the conclusion. (CP 2.183, c. 1902)

So reasoning requires that the premises be consciously recognized, and if premises or processes involved are unconscious, it means that this kind of an operation is not reasoning in a proper sense (CP 5.108, 1903; see also HP 2: 900, 1901; CP 4.476, c. 1903).

Accordingly, it may be maintained that abduction as a form of inference should be developed without appealing to instinct. Abductive inference is a weak form of inference with which possible or plausible candidate hypotheses are drawn by using consciously explicated premises (see Paavola 2004a, 2004b). A paradigmatic example of abductive reasoning is a detective's reasoning (see Fann 1970: 56-59; Eco and Sebeok 1983; Niiniluoto 1999), where various, and minute clues help to delimit and instigate the search for hypotheses, and where the goal is to find such a pattern to which all the relevant information and clues can be fitted (cf. Hanson 1958, 1965; Thagard and Shelley 1997). This does not require necessarily an appeal to instinct, although the detective can also use instinctual clues (see the next chapter). Abduction can be made stronger without instinct, if the whole methodological process, and the way inquirers are able to strategically use all the information available (especially clue-like signs) is taken into account. Abductive reasoning strategies can guide the process, and also the way in which premises are searched for. According to this approach, abductive inference starts from small details and characteristics, and the goal is to find a hypothesis that would explain these details 'as a matter of course' (CP 5.189, 1903; EP 2: 287, 1903). Clues and minute details give hints and suggestions for hypotheses 
(CP 2.755, c. 1905; Burton 2000). So, typically ideas are not searched for in relationship to only one anomalous phenomenon (although the basic formulas of abduction suggest so) but a mass of facts is taken into account at the same time (Paavola 2004a; see also Thagard and Shelley 1997).

I maintain that abduction as a pure form of inference is a good starting point for understanding abductive instinct, in contrast to the position that instinct is a good basis for understanding inference. Abduction as a form of inference means that elements and processes of it must be carefully analyzed. A risk with instinct is that it gives a name for processes that are treated as somewhat mysterious, or which have no proper explanation (cf. CP 6.530-6.531, 1901). In this sense 'instinct' merely amounts to giving a name for those processes that we do not understand; without providing any additional reasons, or evidence for this 'instinct' as a distinguishable, or causally important entity. Peirce's idealistic and theistic justifications for abduction can be interpreted so that operations of mind and operations of nature are somehow analogous; one might then try to explicate this analogy further. But this move leads easily to a rather mysterious interpretation which asserts that human beings can find fruitful hypotheses because they have the 'guessing instinct,' and does not clarify the situation at all. This mysterious guessing power is assumed in order to explain how we humans have managed to find true theories, but this guessing power in itself is not analyzed any further. But I would maintain that the analysis of inferential processes also provides ingredients for a better understanding of the abductive instinct.

\section{The nature of abductive instinct}

I have maintained that Peirce's appeal to instinct leads easily to a rather mysterious view of abduction, especially in his idealistic and theistic justifications for abduction, but also in the naturalistic accounts, if they are not analyzed further. But how are these operations of mind that are analogous to abductive inference supposed to operate? Already in his early writings, Peirce had stated, analogously to his later writings, that such things as emotions, sensations and conceptions are similar to, or closely related to hypothesis (i.e. to abduction) ( $W 1: 289,1865 ; W 1: 471-472$, 1866; $W$ 1: 491, 1866; $W$ 1: 516, 1866; $C P$ 5.291-5.292, 1868; $C P$ 2.643, 1878 ; $C P$ 2.712, 1883; $C P$ 6.145, 1892). I am not, however, so much analyzing these early writings, but inquiring how, through his later writings, the guessing instinct and perceptual judgment can be seen as abductive. 
Abduction can be seen to be operative at the level of inference but also at the 'lower' levels (cf. $W$ 1: 491, 1866; MS 939: 1-4, 1905).

But what are those elements of abductive inference that can be seen as operative in abductive instinct? I maintain that what makes these both processes 'abductive,' is that they both have their basis in 'weak' signs (i.e., clue-like signs) that merely suggest their conclusions or what follows from them. Abduction is near to guessing. But it is not a random process; it deals with those ways to reach a conclusion that are better than pure chance, that is, how to get good guesses. A basic secret for this is the meaning of clues (which phenomena and experience offer), and how these clues are operative in making good guesses. Peirce describes a situation of using minute indications as clues for 'intuition':

A stranger with whom I am dealing may make an impression of being dishonest owing to indications too slight for me to know what they are. Yet the impression may be well founded. Such results are usually set down to "intuition." Though inferential in their nature, they are not exactly inferences. (EP 2: 11-12, 1895)

According to this interpretation, Peircean abductive instinct (like abductive inference) has its basis on small, clue-like signs and the result is a hypothetical idea or interpretation. But in contrast to inference, instinct means that 'premises' or 'inferences' are not deliberately or consciously stated, and the relationship between 'premises' and the guess is an associative connection rather than reasoning. Hence, (1) abductive instinct (or guess) starts from weak signs that instigate the search, and (2) the result is also basically taken as 'weak', i.e. as a hypothetical suggestion. The suggestive starting points can be minute, but there has to be something; abduction does not start from scratch. Peirce is opposing unmediated intuition (Anderson 1987: 37-39), and this means that there have to be some signs to start the process. Facts or surprising phenomena suggest the theory or the idea (see e.g. $E P$ 2: 287,$1903 ; C P$ 5.144-5.145, 1903; $C P$ 8.209 , c. 1905). Human beings, especially when they are well acquainted with the subject-area in question, are, to varying degrees, good at recognizing clues, and using these clues and other information in searching for new ideas. This account is present in Peirce's detective story concerning the guessing instinct (see above). On the one hand Peirce describes the operation of the guessing instinct as if there were no reasons for his guess; he did not notice any clues of the crook while he was observing the suspects. On the other hand, the point of this story was that people can derive 'from observation[,] strong intimations of truth' without being conscious of it. As I interpret this, it does not mean that Peirce had no reasons for 
his guess, but that he had no consciously recognized reasons or intimations for it (see also Eco and Sebeok 1983: 18; Burton 2000: 154-155).

The result of activity of the abductive instinct is basically a guess, i.e., a conjectural hypothesis. Abduction merely suggests that something may be (CP 5.171-5.172, 1903; see also Anderson 1987: 34-35; Paavola 2004b) also in the case of instinct. According to Peirce, the acceptance of the hypothesis can range 'from a mere expression in the interrogative mood' to 'uncontrollable inclination to believe,' but, in all cases, the result is a plausible hypothesis $(C P 6.469,1908)$. And plausibility means that the inquirer has some (weak) reasons for regarding the hypothesis favorably (see $C P$ 8.222, c. 1910). Also in those cases, as in Peirce's detective story, where the inquirer is subjectively very confident that the guess is true and yet is unable to specify the grounds, it is still guessing.

Not only the guessing instinct, but also perceptual judgment is abductive in form $(C P$ 5.181, 1903). According to Peirce, perception can be analyzed with a formula that is similar to abduction (see also Hoffmann 1999: 284):

A well-recognized kind of object, $\mathrm{M}$, has for its ordinary predicates $\mathrm{P}[1], \mathrm{P}[2]$, $\mathrm{P}[3]$, etc., indistinctly recognized.

The suggesting object, $\mathrm{S}$, has these same predicates, $\mathrm{P}[1], \mathrm{P}[2], \mathrm{P}[3]$, etc.

Hence, $\mathrm{S}$ is of the kind M. (CP 8.64, 1891)

This sequence is abductive in form, but '[i]n perception, the conclusion has the peculiarity of not being abstractly thought, but actually seen, so that it is not exactly a judgment, though it is tantamount to one.' ( $C P$ 8.65, 1891; also HP 2: 899-900, 1901; CP 6.522-524, 1901; CP 5.194, 1903; $M S$ 856: 6-8, 1911). This 'abductiveness' of perception is more evident in those visual illusions of reversible figures (e.g., in the Necker Cube) where the same visual data can be interpreted in various ways (see $C P 5.182-5.185,1903)$. According to my interpretation, these reversible figures show that, in perception, visual clues are organized by using some deeper level interpretation (or 'hypothesis') that makes them understandable (cf. Shelley 1996; Thagard and Shelley 1997; Brogaard 1999, 136-140). This perceptual process is similar to abduction, where facts and clues are organized anew to explain some surprising phenomena ( $E P$ 2: 287, 1903; PPM 282-283; cf. CP 7.36, c. 1907). When we see things, we see this intepretation, so in this sense, it is different from inference (where the conclusion is abstractly drawn or thought). But visual illusions show that seeing is not unequivocal; in a sense it is hypothetical, depending on how we organize the whole pattern (see Hanson 1958). 
My separation of abductive inference from instinct is not intended to suggest that abductive inference is necessarily a better model in comparison to abductive instinct. Quite the contrary, Peirce himself gives many convincing arguments for the view that, in many cases, instincts are better guides than consciously performed inferences; for example:

Most men are incapable of strong control over their minds. Their thoughts are such as instinct, habit, association suggest, mainly. Their criticism of their thoughts is confined to reconsideration and to asking themselves whether their ideas seem reasonable. I do not call this reasoning: I call it instinctive reflexion. For most purposes it is the best way to think; for instinct blunders far less than reason. Reasoners are in danger of falling into sophistry and pedantry. Our instinctive ways of thinking have become adapted to ordinary practical life, just as the rest of our physiology has become adapted to our environment. (CP 7.606, 1903)

The guessing instinct might be more effective and fruitful than reasoning. When Peirce describes the guessing instinct (with non-conscious clues), he defends it with the argument that

[e]verybody knows how self-consciousness makes one awkward and may even quite paralyze the mind.... At any rate my own experience is that selfconsciousness, and especially conscious effort, are apt to carry me to the verge of idiocy and that those things that I have done spontaneously were the best done. (CP 7.45, c. 1907; see also NEM 3: 215, 1910)

Instinct can be more important if quick and practical decisions are needed because then one does not have time for more thorough 'scientific' analysis (CP 7.606, 1903; NEM 4: 36, 1902; MS 637: 11-12, 1909). Peirce argues that animal instincts are adapted to their purpose and are highly accurate in these respects; but reasoning is not bound to immediate practical concerns and utilities (NEM 4: 36, 1902). Reasoning is more amenable to error, but also needed when old solutions are not enough (CP 6.497, c. 1906; CP 2.176-178, c. 1902; CP 7.380, c. 1902; NEM 4: 217).

\section{The conflation of instinct and inference in Peirce's later writings}

I think there is reason to say that in his later writings Peirce never satisfactorily resolved the relationship between instinct and inference, not even to his own mind; that he continued to have problems finding satisfactory justification for abduction (Fann 1970: 51-54). In his later writings, Peirce emphasized abduction as a weak form of inference, and it needed some strengthening (Burton 2000; Paavola 2004b). Abduction 
'merely suggests that something may be' (CP 5.171-172, 1903); it is near to guessing, or even the same as guessing (e.g. HP 2: 878-879, 1900; HP 2: 898-899, 1901; NEM 3: 203-204, 1911). So abduction needs something more to be a realistic model for discovery (i.e., to tell how new ideas are generated). In real life, human beings have found good hypotheses more efficiently and quickly than pure chance would allow, so there must be an explanation how this happens. Instinct can then be seen as one possible hypothesis for explaining our success at finding fertile ideas. Peirce himself often stated this position explicitly as a hypothesis $(C P 7.39$, c. 1907; $C P$ 7.220, 1901; CP 1.121, c. 1896; MS 652: 24, 1910), so it seems that it is only one possible explanation, and Peirce hinted that there may be other alternative explanations (Fann 1970: 37, 54).

This instinctual strengthening of abduction surely fitted with Peirce's metaphysical ideas; with his synechism, agapism, and his theistic ideas. Synechism and agapism (and also theistic arguments) gave backing to the idea that there is some sort of a tendency in human mind to find out true theories, whatever is the exact explanation for this tendency. There were many similar discussions in Peirce's time, in biology and social theory, concerning such concepts as "instinct," "reason," "inference", and "evolution", which gave background to his thoughts. But clearly it was a problem for Peirce that logic seems here to need some backing from psychology (see $M S$ 637: 9-10, 1909; $M S$ 652: 24, 1910), that is, we have to suppose that human beings really have this instinct in order to explain how hypotheses are abductively found.

The turn of the century is a kind of a transitional period in Peirce's thought concerning abductive instinct. Before this period, Peirce made a clear separation between inference and instinct. And after that, without making an abrupt change, Peirce more emphatically stressed the instinctual nature of abduction; it seems that he always wanted to emphasize inferential nature of abduction as well. At least in 1901 he had already stated very clearly that instinct is an important element in explaining the success of abduction:

[I]t is a primary hypothesis underlying all abduction that the human mind is akin to the truth in the sense that in a finite number of guesses it will light upon the correct hypothesis. (CP 7.220, 1901)

In 1908, when he stated that abduction (then with the name 'retroduction') is 'the spontaneous conjecture of instinctive reason' (CP 6.475, 1908), he also insisted that, in order to be 'argumentation,' the process must proceed upon definitely formulated premises. So, if the premises are not explicitly formulated, it is not argumentation (in a proper sense) 
but 'argument,' which means 'any process of thought reasonably tending to produce a definite belief' (see $C P 6.456$ and $C P 6.469,1908$ ).

On the whole, the basic argument for the need of the guessing instinct is quite weak (see e.g., $C P$ 7.220, 1901; HP 2: 900-901, 1901; CP 5.591, 1903). Peirce argues that we human beings could not have reached our theories by pure chance. There simply is not enough time. So one needs to assume some sort of an instinct that has helped us to find true theories. And if animals have various instincts, why not to presume that we as humans have instincts for finding true theories (because this is so important for our survival)? And, according to Peirce, it seems also that at least the best scientists actually have this sort of an instinct for finding good hypotheses. I think that Peirce's argument points out that we as human beings must have had some way of finding good ideas and theories more effectively than by pure chance. But let us examine the argument more closely; what evidence do we have that this is because of some sort of an instinct? Instinct is only one possible explanation here, and a rather indefinite explanation. And even though it would be admitted that we humans may have some kind of instinct, or various instincts that help us to find good theories, why should this concern abduction as an inference? We could also assume that theories are found with guessing instinct, but distinguish this from abductive inference. A historical question of how human beings have managed to find successful and true theories is not the same as a question about the nature of abductive inference, or its justification. We could argue that human beings must have a way of finding good ideas and hypotheses more effectively than by pure chance, and still preserve the distinction between abductive inference and abductive instinct.

\section{Conclusion}

Peirce's writings are a rich source of inspiration for theories concerning abduction and discovery. I think that his writings are like material for reversible figures that can be organized in various ways. Peirce's writings leave room, for example, for various interpretations concerning abductive instinct. I have argued that Peirce did not resolve the relationship between inference and instinct in a clear-cut manner in his later writings.

The interpretation that I advocate is to distinguish abductive instinct and abductive inference, which suggests that abduction can be developed further as a 'pure' form of inference: Various aspects of it can be analyzed further, for example, the nature of its premises, the inferential relationships within it, the strength and validity of it, how abductive inferences 
are used. That is, in Peircean terms, the grammar, the critic, and the methodeutic of abductive inference should all be further examined (see Paavola 2004b).

The proposal that abductive inference should be developed further as a mode of inference does not mean that abductive instinct should be neglected, quite the contrary. Peirce analyzes many phenomena under the guessing instinct that are of interest to modern cognitive sciences, starting with the idea that human beings can use, in their problem solving, information of which they are not conscious. Peirce, of course, did not have at his disposal many of those conceptions that are attractive to the modern reader from this perspective (for example the notion of 'tacit knowledge', or modern conceptions of expertise). The idea of abductive instinct could be analyzed further by using these modern notions.

In actual problem-solving situations, human beings often use a mixture of abductive inference and abductive instinct. Consciously held premises and reasonings interact with more vaguely noticed and controlled clues and suggestions, and rather than using these in a linear fashion, various pieces are combined in parallel (Thagard 2000: 2-3). Abductive instinct is especially important when quick and spontaneous decisions are needed on the basis of the inquirer's previous experience. Abductive inference gives means for analyzing and organizing the abductive search explicitly. So, both abductive instinct and abductive inference are important when good ideas or hypotheses are searched for. ${ }^{3}$

\section{Notes}

1. Peirce used various names for this third mode of inference throughout his long career; Reasoning à posteriori (e.g. $W$ 1: 180, 1865; $W 1$ : 266-267, 1865), Hypothesis (e.g. $W 1$ : 283, 1865; CP 1.559, 1867; HP 2: 878-879, 1900), Abduction (e.g. HP 2: 898-899, 1901; $C P$ 7.202, 1901; CP 5.188-189, 1903; CP 8.209, c. 1905), Presumption (e.g. CP 2.776$777,1902)$, Retroduction (CP 1.68, c. 1896; 1898; CP 6.469-6.470, 1908; CP 8.385$8.388,1913)$ (More thoroughly, see Bergman and Paavola, 2003). I use systematically the term 'abduction' because it is the established term nowadays.

2. Partly published in $C P 7.36-7.48$, c. 1907; see also Eco and Sebeok 1983 where this story and article is thoroughly described.

3. I would like to thank Matti Sintonen, Mats Bergman, and Hal White for insightful comments on this paper. I also want to thank the Finnish Cultural Foundation for supporting my work with a grant.

\section{References}

Anderson, Douglas R. (1986). The evolution of Peirce's concept of abduction, Transactions of the Charles S. Peirce Society 22 (2), 145-164. 
-(1987). Creativity and the Philosophy of C. S. Peirce. Dordrecht: Martinus Nijhoff Publishers.

Bergman, Mats and Paavola, Sami (eds.) (2003-). The Commens Dictionary of Peirce's Terms: Peirce's Terminology in His Own Words. http://www.helsinki.fi/science/ commens/dictionary (accessed August 27, 2004).

Braithwaite, R. B. (1934). Review of Collected Papers of Charles Sanders Peirce (vols. 1-4). Mind 43, 487-511.

Brogaard, Berit (1999). Peirce on abduction and rational control. Transactions of the Charles S. Peirce Society 35 (1), 129-155.

Burks, Arthur W. (1946). Peirce's theory of abduction. Philosophy of Science 13, 301-306.

Burton, Robert B. (2000). The problem of control in abduction. Transactions of the Charles S. Peirce Society 36 (1), 149-156.

Eco, Umberto and Sebeok, Thomas A. (eds.) (1983). The Sign of Three. Dupin, Holmes, Peirce. Bloomington: Indiana University Press.

Fann, K. T. (1970). Peirce's Theory of Abduction. The Hague: Martinus Nijhoff.

Flach, Peter A. and Kakas, Antonis C. (2000). Abductive and inductive reasoning: Background and issues. In Abduction and Induction: Essays on their Relation and Integration, Peter A. Flach and Antonis C. Kakas (eds.), 1-27. Dordrecht: Kluwer Academic Publishers.

Frankfurt, Harry G. (1958). Peirce's account of inquiry. The Journal of Philosophy 55 (14), 588-592.

Hanson, Norwood R. (1958). Patterns of Discovery: An Inquiry into the Conceptual Foundations of Science. Cambridge: Cambridge University Press.

- (1965). Notes toward a logic of discovery. In Perspectives on Peirce, Richard J. Bernstein (ed.), 42-65. New Haven/London: Yale University Press.

Hoffmann, Michael (1999). Problems with Peirce's concept of abduction. Foundations of Science 4 (3), 271-305.

Kapitan, Tomis (1990). In what way is abductive inference creative? Transactions of the Charles S. Peirce Society 26 (4), 499-512.

- (1992). Peirce and the autonomy of abductive reasoning. Erkenntnis 37, 1-26.

- (1997). Peirce and the structure of abductive inference. In Studies in the Logic of Charles Sanders Peirce, Nathan Houser, Don D. Roberts and James Van Evra (eds.), 477-496. Bloomington: Indiana University Press.

Kim, Jungsub and Cunningham, Donald J. (2003). A syllogism for formulating hypotheses. Semiotica 144 (1/4), 303-317.

Nickles, Thomas (1980). Introduction: Scientific discovery and the future of philosophy of science. In Scientific Discovery, Logic, and Rationality, Thomas Nickles (ed.), 1-59. Dordrecht: D. Reidel Publishing Company.

Niiniluoto, Ilkka (1999). Abduction and geometrical analysis: Notes on Charles S. Peirce and Edgar Allan Poe. In Model-Based Reasoning in Scientific Discovery, Lorenzo Magnani, Nancy J. Nersessian, and Paul Thagard (eds.), 239-254. New York: Kluwer Academic / Plenum Publishers.

Paavola, Sami (2004a). Abduction as a logic of discovery: The importance of strategies. Foundations of Science 9 (3), 267-283.

- (2004b). Abduction through grammar, critic and methodeutic. Transactions of the Charles S. Peirce Society 40 (2), 245-270.

Peirce, Charles S. (1929). Guessing. Hound and Horn 2 (3), 267-282.

- (1931-1966). The Collected Papers of Charles S. Peirce, 8 vols., C. Hartshorne, P. Weiss, and A. W. Burks (eds.). Cambridge: Harvard University Press. [Reference to Peirce's papers will be designated $C P$ followed by volume, paragraph number, and year written.] 
- (1967). Manuscripts in the Houghton Library of Harvard University, as identified by Richard Robin, Annotated Catalogue of the Papers of Charles S. Pierce. Amherst: University of Massachusetts Press, 1967. [Reference to Peirce's manuscripts will be designated MS followed by the manuscript number, page number, and, where available, year written.]

- (1976). The New Elements of Mathematics, 4 vols., C. Eisele (ed.). Berlin: Mouton; Atlantic Highlands, NJ: Humanities Press. [Reference to Peirce's New Elements will be designated $N E M$ followed by volume and page numbers.]

-(1982-). Writings of Charles S. Peirce: A Chronological Edition, 6 vols., C. Hartshorne, P. Weiss, and A. W. Burks, and the Peirce Edition Project (eds). Bloomington: Indiana University Press [Reference to Peirce's writings will be designated $W$ followed by volume and page numbers.]

- (1985). Historical Perspectives on Peirce's Logic of Science. A History of Science, 2 vols., Carolyn Eisele (ed.). Berlin: Mouton Publishers. [Reference to Historical Perspectives will be designated $H P$ followed by volume and paragraph numbers.]

-(1992). Essential Peirce. Selected Philosophical Writings, vol. 1 (1867-1893), N. Hauser and C. Kloesel (eds.). Bloomington: Indiana University Press. [Reference to Volume 1 of Essential Peirce will be designated EP 1.]

-(1997). Pragmatism as a Principle Method of Right Thinking. The 1903 Harvard Lectures on Pragmatism, P. Turrisi (ed.). Albany: State University of New York Press. [Reference to Peirce's Pragmatisim will be designated PPM.]

— (1998). Essential Peirce. Selected Philosophial Writings, vol. 2 (1893-1913), Peirce Edition Project (eds.). Bloomington: Indiana University Press. [Reference to Volume 2 of Essential Peirce will be designated EP 2.]

Roth, Robert J. (1988). Anderson on Peirce's concept of abduction: Further reflections, Transactions of the Charles S. Peirce Society 24 (1), 131-139.

Shanahan, Timothy (1986). The first moment of scientific inquiry: C. S. Peirce on the logic of abduction, Transactions of the Charles S. Peirce Society 22 (4), 450-466.

Shelley, Cameron (1996). Visual abductive reasoning in archeology. Philosophy of Science 63 (2), 278-301.

Thagard, Paul (1981). Peirce on hypothesis and abduction. In Proceedings of the C. S. Peirce Bicentennial International Congress, K. L. Ketner, J. M. Randsell, C. Eisele, M. H. Fisch, and C. S. Hardwick (eds.), 271-274. Lubbock: Texas Tech Press.

- (2000). Coherence in Thought and Action. Cambridge, Massachusetts: A Bradford Book, MIT Press.

Thagard, Paul and Shelley, Cameron (1997). Abductive reasoning: Logic, visual thinking, and coherence. In Logic and Scientific Methods, M. L. Dalla Chiara, K. Doets, D. Mundici, and J. van Bentham (eds.), 413-427. Dordrecht: Kluwer. http://cogsci.uwaterloo.ca/ Articles/Pages/\%7FAbductive.html (accessed August 27, 2004).

Sami Paavola (b. 1964) is a reseacher at the Center for Research on Networked Learning and Knowledge Building in the department of Philosophy at the University of Helsinki 〈sami.paavola@helsinki.fi〉. His interests are abduction, Peirce, and theories of inquiry and learning. His publications include 'Abduction through grammar, critic and methodeutic' (2004); and 'Abduction as a logic and methodology of discovery: The importance of strategies’ (2004). 
Copyright of Semiotica is the property of Walter de Gruyter GmbH \& Co. KG. and its content may not be copied or emailed to multiple sites or posted to a listserv without the copyright holder's express written permission. However, users may print, download, or email articles for individual use. 